\title{
Current Middle \& Upper Palaeolithic research in the southern Caucasus
}

\section{Nicholaz Tushabramishvili, Daniel S. Adler, Orfr Bar-Yosef \& AnNa Belfer-Cohen*}

Since 1997 an international research team has been reinvestigating Ortvale Klde, a Palacolithic rockshelter located in the Georgian Republic (FIGURES 1 \& 2). The main goals of this new collaborative project have been to document Middle and Upper Palaeolithic patterns of lithic reduction, land-use and mobility, and to date the Middle-Upper Palaeolithic chronological boundary. To date, five seasons (19972001) of excavation and analysis have been conducted. During this time we have recovered large samples of lithic and faunal material, identified the stratigraphic: boundary between the Middle and Upper Palaeolithic and collected over 100 charcoal, bone and lithic samples for dating via Accelerator Mass Spectrometry (AMS), Thermoluminescence (TL) and Electron

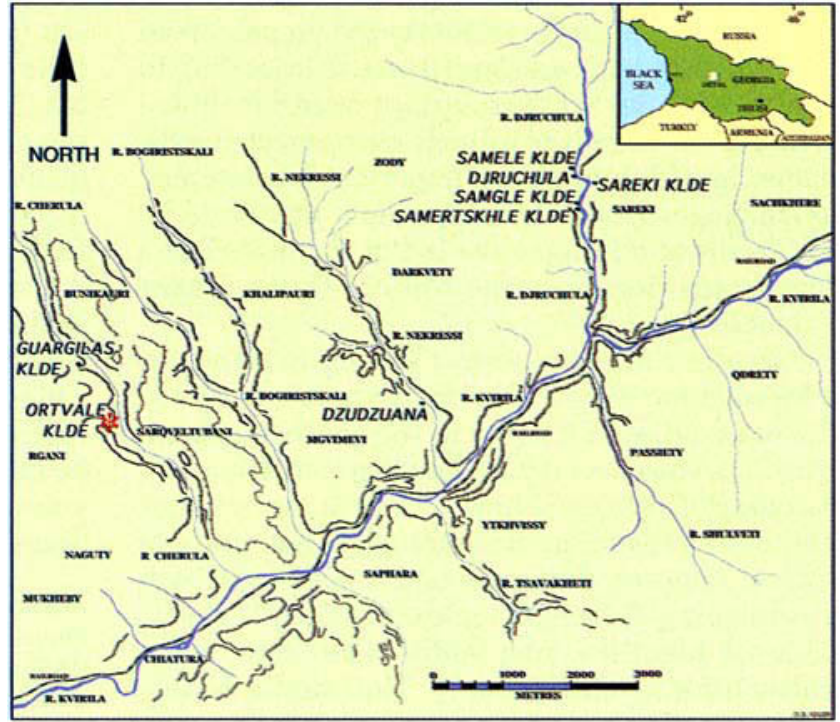

FIGIIRE 1 (top). Map of the Georgian Republic with detail of the Kvirila River Vallev and important Pulaeolithic localities (italics).

FIGURE 2 (middle). View of Ortvale Klde from the east.

FIGURE 3 (bottom). Composite section from the southern chamber (sub-layers not indicated).

* Tushabramishvili, Georgian State Museum, Department of Archacology, 3 Purtseladze. St., 380007 Tbilisi, Georgian Republic: Adler \& Bar-Yosef. Harvard University, Department of Anthropulngy, Peabody Museum, 11 Divinity Avenue, Cambridge MA 02138, USA.

dsadler@fas.harvard.edu obaryos@fas.harvard.edu Belfer Cohen, Institute of Archaeology, Hebrew University, Mt. Scopus. Jerusalem, 91905 Israel. belfer@h2.hum.huji.ac.il

A.vTIQLITY 76 (2002): 927-8
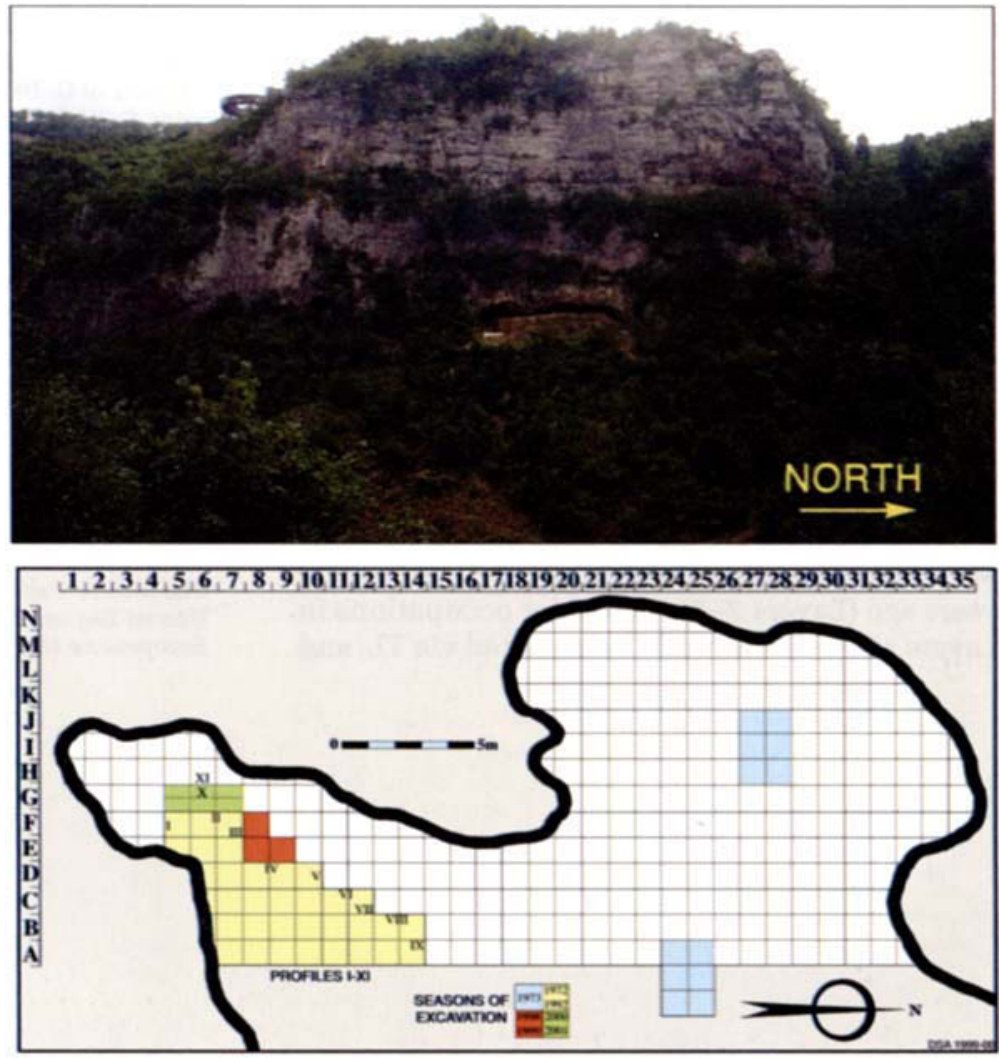
Spin Resonance (ESR). Although aspects of our research remain incomplete, we can offer several preliminary observations that help place the Palaeolithic record of the southern Caucasus within a broader regional context.

Previous research in the Georgian Republic led to the identification of several distinct Middle Palaeolithic cultural variants based on perceived differences in lithic and faunal assemblages (Liubin $1977 ; 1989)$, but these groupings were developed without the benefit of reliable chronometric estimates. In addition, several important 'transitional' assemblages from the region, now known to be the result of mixing, have led to the notion of a local transition from the Middle to the Upper Palaeolithic.

Ortvale Klde is a perfect setting in which to address these issues. Thus far we have completed the excavation of $6 \mathrm{sq}$. $m$ in the southern chamber. This work has led to the documentation and recovery of $\sim 30,000$ lithics, $\sim 5,000$ faunal remains and numerous micromorphological and mineralogical samples, the systematic studies of which are on-going. During the re-excavation of Ortvale Klde we identified five Middle and three Upper Palaeolithic layers (FIGURF 3). The Middle Palaeolithic layers (10-9 \& 7-5) all contain lithic assemblages characterized as uni-directional Levallois industries dominated by scrapers with a high incidence of truncated facetting. Previous palaeontological analyses indicate that the faunal assemblage is dominated by Capra caucasica $(\sim 85 \%)$. Our on-going zooarchaeological analysis is testing this claim while also investigating hunting and faunal processing behaviours. The Upper Palaeolithic assemblages are dominated by small backed bladelets, endscrapers and several bone points, but they cannot be characterized as Aurignacian. Based on our current excavations, no case can be made for a 'transitional' industry at the site.

AMS and TL estimates allow us to date the Middle Palaeolithic occupations to $\sim 44-35,000$ years ago (Layers 7--5). The older occupations in Layers 10-9 are currently being dated via TL, and
Layer 8 is sterile. These same methods allow us to date the Upper Palaeolithic occupations (Layers $4-2$ ) to $\sim 32-21,000$ years ago. These data suggest the persistence of Neanderthals in the region and the late arrival of Upper Palaeolithic peoples.

Based on our initial research at Ortvale Klde we believe that Neanderthals occupying the southern Caucasus were members of a larger prehistoric social and mating network demarcated by the Caucasus Mountains to the north and the Taurus-Zagros to the south (Adler \& 'Tushabramishvili in press). Interactions with Neanderthal populations in the northern Caucasus are only suggested by several finds from Mezmaiskaya Cave. It also appears that the southern Caucasus served as one of the last large territories occupied by Neanderthals. The abrupt shift from the Middle-Upper Palaeolithic at Ortvale Klde cannot be characterized as an in situ cultural transition. Instead it appears Upper Palaeolithic: peoples entered the region approximately 32,000 years ago without significant, if any, overlap with Neanderthal populations.

Acknowledgements. Our research is supported by the Leakey Foundation; the American School for Prehistoric Research (Peabody Museum. Harvard University); the Mellon Foundation (Harvard University); the Davis Center for Russian Studies (Harvard University); and the Wenner-Gren Foundation for Anthropological Research (New York). Our thanks go out to our Georgian colleagues and we wish to recognize efforts of G. Bar-Oz, E. Boaretto, D. Lordkipanidze, N. Mercier, S. Weiner and A. Smith.

\section{References}

ADLER, U.S. \& N. TISHABRAMISHVIlI. In press. Middle Palaeolithic patterns of settlement and subsistence in the? southern Caucasus, in N. Conard (ed.), Middle Palacolithic settlement dynamics. Tübingen: Kerns Verlag. Tübingen Publications in Prehistory.

LIU!BIN, V.P. 1977. Mustierskie kul'turi Kavkaza (Mousterian Cultures of the Caucasus). Leningrad: Nauka. 1989. Palenlit Kavkaza (Paleolithic of the Caucasus), in P.I. Boriskovsky (ed.). Paleolit Kavkaza i Severnoi Azii (The Palaeolithic of the Caucasus and Northern Asia): 9142. Leningrad: Nauka.

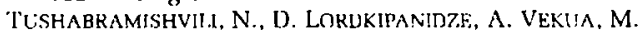
TVALCHERLIDZE, A. MLSSKHFLISHVILI \& D.S. ADLER. 1999. The Middle Palacolithic rockshe!ter of Ortvale Klde. Inereti Region, The Georgian Republic, Préhistoire Europenne 15: 65-77. 